\title{
Influence of Sound Vibration on Diamond-Like Carbon Deposition Rate
}

\author{
Syed Md. Ihsanul Karim, ${ }^{1}$ Mohammad Asaduzzaman Chowdhury, ${ }^{2}$ and Md. Maksud Helali ${ }^{3}$ \\ ${ }^{1}$ Bangladesh Industrial Technical Assistance Centre (BITAC), Ministry of Industries, Dhaka 1208, Bangladesh \\ ${ }^{2}$ Department of Mechanical Engineering, Dhaka University of Engineering and Technology, Gazipur 1700, Bangladesh \\ ${ }^{3}$ Department of Mechanical Engineering, Bangladesh University of Engineering and Technology, Dhaka 1000, Bangladesh
}

Correspondence should be addressed to Mohammad Asaduzzaman Chowdhury, asadzmn2003@yahoo.com

Received 14 February 2012; Accepted 19 March 2012

Academic Editors: J.-i. Jang and A. Postelnicu

Copyright (C) 2012 Syed Md. Ihsanul Karim et al. This is an open access article distributed under the Creative Commons Attribution License, which permits unrestricted use, distribution, and reproduction in any medium, provided the original work is properly cited.

\begin{abstract}
This work examines how vapor-deposited coating of DLC (partially diamond) on stainless steel 304 substrate is affected by the sound vibration. For this, a specially designed chemical vapor deposition (thermal CVD and hot filament) apparatus having facility of generating sound vibration at different frequency is fabricated. A coating of DLC (partially diamond) has been deposited on the substrate, and the characterization of the coating has been done by SEM, EDX, and XRD. The coating of carbon is identified by EDX, and the allotropic forms of graphite and diamond peaks of carbon are found by XRD analysis. By SEM analysis, it is found that the microstructures of deposited coatings are more compact and smoother under vibration than those in absence of vibration. The experiments were conducted under different ranges of vibration including sonic and ultrasonic range. Studies have shown that the growth rate of deposited coating on a unit area is higher under vibration than that in absence of vibration. It is found that deposition rate varies with the distance between substrate and activation heater and frequency of vibration. The deposition rate does not vary significantly with the change of frequency in the sonic range. The amount of deposition under ultrasonic vibration increases significantly with the frequency of vibration upto 5-6 mm distance between substrate and activation heater. Within this distance, the difference of deposition rate under vibration and without vibration conditions increases almost linearly with the increase of frequency of vibration. Beyond this distance, the effect of frequency on deposition rate becomes almost constant. In addition, the higher the distance, the less is the effectiveness of frequency of vibration on the deposition rate in that range. The deposition rate increases due to the extra vibration of sound added to the system which may enhance the activation energy by increasing its kinetic energy. The experimental results are compared with those available in the literature, and physical explanations are provided.
\end{abstract}

\section{Introduction}

Chemical vapor deposition (CVD) is a process in which a solid material formed from a vapor phase by chemical reaction is deposited on a heated substrate. The deposited material is obtained as a coating of multicrystal layer. The controlling parameters in CVD process are surface kinetics, mass transport in the vapor, thermodynamics of the system, chemistry of the reaction and processing parameters like temperature and pressure. The deposition rate which is the prime limiting factor in a CVD process is mainly controlled by the formation of required species to be deposited and its transportation in the vapor and surface kinetics [1-3].
Several authors [4-7] observed that the quality and the rate of deposition depend on temperature of the substrate and filament, gas flow rate, gas composition (reactants), and chamber pressure. Different arrangements and techniques such as centrifugation, vertical vibration of the substrate, hydrogen and argon inclusion, change of gas injecting location, and formation of plasma have been studied by different authors [8-12]. The effects of operating parameters on the deposition rate were also investigated for these techniques. A study is carried out to observe the effect of ultrasonic vibration on electrochemical deposition [13]. However, the effect of sound vibration on CVD process is yet to be investigated. Kinetic energy increases by adding extra energy of sound 
TABLE 1: Experimental variables.

\begin{tabular}{lcc}
\hline S. number & Parameters & Range \\
\hline$(1)$ & Pressure & $20-30 \mathrm{Torr}$ \\
$(2)$ & Substrate (nicrom) heater & \\
temperature & $800-1000^{\circ} \mathrm{C}$ \\
$(3)$ & Activation (tungsten) heater \\
temperature & $1800-2000^{\circ} \mathrm{C}$ \\
$(4)$ & Substrate (nicrom) heater power & $1000 \mathrm{watt}$ \\
$(5)$ & Substrate (nicrom) heater voltage & $80-100 \mathrm{~V}$ \\
$(6)$ & Substrate (nicrom) heater current & $7-10 \mathrm{amp}$ \\
$(7)$ & Activation (tungsten) heater power & $200 \mathrm{watt}$ \\
$(8)$ & Activation (tungsten) heater voltage & $5-7 \mathrm{~V}$ \\
$(9)$ & Activation (tungsten) heater current & $25-35 \mathrm{amp}$ \\
$(10)$ & Flow rate (CH ${ }_{4}$ gas) & $0.1-1.5 \mathrm{~L} / \mathrm{min}$ \\
$(11)$ & Gap between substrate and & $2.5-8.0 \mathrm{~mm}$ \\
$(12)$ & Tungsten heater & $0-110 \mathrm{kHz}$ \\
$(13)$ & Sound frequency & $3-10 \mathrm{minutes}$ \\
$(14)$ & Deposition duration & $22 \mathrm{~mm} \times 14 \mathrm{~mm}$ \\
& Substrate size & $\times 1.15 \mathrm{~mm}$ \\
\hline
\end{tabular}

which may increase the deposition rate. This extra kinetic energy may enhance the chemical activity by overcoming the potential barrier and increases the mass transport of the species.

The effect of sound vibration increases with the increase of density of media, through which it travels. Therefore, the CVD process has been selected, as CVD does not usually require very low pressure, which is necessary for PVD system. Consequently, the vacuum system in CVD is simpler and less costly. Comparing with other CVD process, thermal CVD (hot filament) is relatively inexpensive, and experiments can be readily carried out. Therefore, in this study an attempt is made to investigate the effect of sound vibration, in particular, the frequency of vibration on the deposition rate. In addition to deposition rate, the quality of deposited coating is also investigated. Deposition in absence of vibration was investigated first, and then the results were compared with the results obtained under different frequency of vibrations. Some parameters that affect the deposition were also inspected.

\section{Experimental}

A thermal chemical vapor deposition (hot filament) setup (Figure 1) was designed and fabricated. The setup is a CVD system comprises of a reactor chamber supported by some subassemblies and sub systems. The subassemblies are (i) heater, (ii) sound generating system, (iii) connector and (iv) cooling line, and the subsystems are (i) gas evacuation system, (ii) electric supply system, (iii) heating system, (iv) cooling system, (v) gas supplying system, (vi) substrate cleaning system (vii) measuring system, and (viii) structure and handling system. These arrangements of the experimental setup (Figure 1) are similar to the conventional thermal chemical vapor deposition (hot filament) unit.

A separate arrangement is designed and fabricated for generating sound shown, in Figure 2. The signal of sound vibration is generated by signal generator. After amplification by an amplifier, this signal of sound vibration passes through the wire to the piezoelectric horn, placed inside the vibration generating chamber. There are two insulated leak proof connectors in the vibration generating chamber, which facilitate to pass the sound signal from outside to inside. The sound is generated in the piezoelectric horn since it gets the sound generating signal from signal generator and passes through hollow pipe towards the substrate. There is a provision to monitor the frequency and amplitude of the generated sound vibration by an oscilloscope, connected parallel with the input wire.

The deposition rates of the coating per unit area per unit time were calculated from the weight difference of substrate before and after deposition. The surface morphologies of the deposited coatings were analyzed by SEM attached with energy dispersive X-ray spectrometry (EDX). X-ray diffraction (XRD), with target of $\mathrm{Mo}(\mathrm{Zr}), 30 \mathrm{kV} / 20 \mathrm{~mA}$, and an incident angle of $1^{\circ}$, is used to study the composition of coated material.

Experimental conditions are shown in Table 1. During tests, each experiment was repeated several times. In the figures, dispersion of test results at each point is also shown.

\section{Results and Discussions}

Figure 3 shows the variation of deposition rate under vibration and without vibration in the range of frequency 0 to $110 \mathrm{KHz}$ at a distance of $5 \mathrm{~mm}$ between substrate and activation heater. At each frequency, at least five experiments were conducted to get an average deposition rate. All these data are presented in the figure. From these data, a considerable increase in deposition rate on unit area is observed for deposition under vibration compared to that under no vibration.

From this figure, it is observed that deposition rate increases from 0 at no to approximately $6 \mathrm{KHz}$. From $6 \mathrm{KHz}$, the deposition rate increases linearly up to approximately $20 \mathrm{KHz}$, and after that the steepness of the curve shows higher deposition rate, and finally increment rate reduces to almost negligible amount up to the observed range. The higher deposition rate under vibration might be due to the fact that mechanical and pressure wave of propagated sound towards the substrate enhances the mass transfer rate of depositing carbon species. The variation of the rate of increment of deposition at different frequency ranges might be due to the change of resultant vibration of carbon particles which depends on the wave length of the sound at different frequency and the particle size and the mass of the species. It is observed that deposition rate under sonic range of sound vibration does not vary significantly with frequency of vibration. But the rate of deposition under ultrasonic vibration increase significantly with frequency of vibration. 


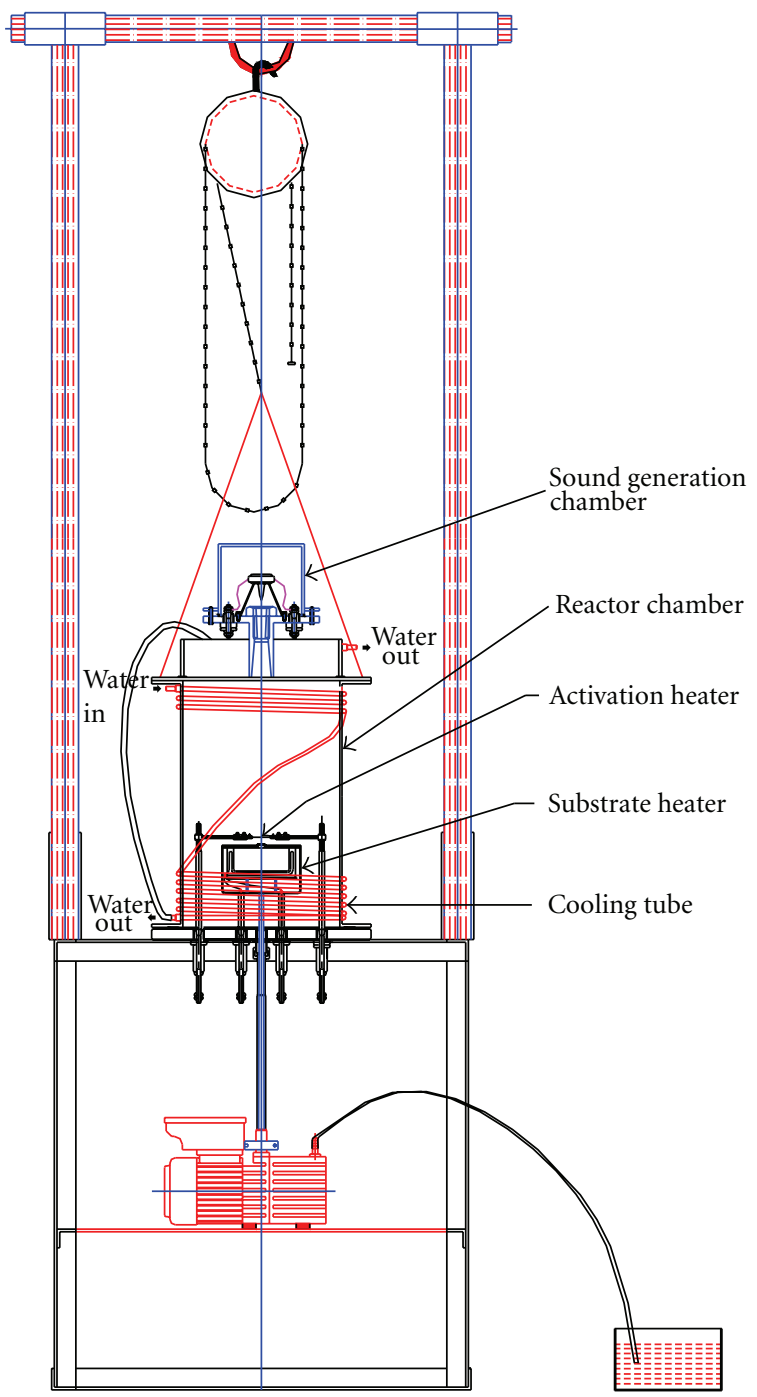

FIGURE 1: Schematic diagram of chemical vapor deposition (hot filament) setup.

Figure 4 shows the variation of deposition rate with the distance between substrate and activation heater under vibration and no vibration. From this figure, it is observed that deposition rate under vibration is higher than that under no vibration at identical conditions within the observed range. Curves 1, 2, 3, and 4 of Figure 4 are drawn for $4 \mathrm{~mm}$ to $8 \mathrm{~mm}$ distance between substrate and activation heater and under the vibration of $0,40,70,90$, and $110 \mathrm{kHz}$, respectively. From this figure, it is shown that the deposition rate decreases linearly with the increase of distance between substrate and activation heater up to $6 \mathrm{~mm}$, and after that it remains almost constant. This may be due to the numbers of activated carbon species and atomic hydrogen are more near the activation tungsten heater. It is observed that the decreasing deposition rate with distance (up to a certain distance) is higher for high frequency in comparison to lower frequency. This is because the higher the intensity, the higher is the variation of energy with respect to distance. For a particular distance, the deposition rate is high for higher frequency. This is because, at higher frequency, the intensity of sound is higher, and thus the energy transmitted from sound to the particle is higher. For all frequencies, when the distance is more than $5.5 \mathrm{~mm}$ the deposition rate is almost constant. That means, beyond this distance, the effect of frequency on deposition rate is negligible. This may be due to the dissipation of sound energy to the environment reaches to a mean value (for any intensity) at a distance more than $5.5 \mathrm{~mm}$.

Figure 5 shows the comparison of micrographs of coated surface under vibration and without vibration at 200 magnifications. The left-side view of this figure is the coated surface deposited under vibration $(40 \mathrm{kHz})$, and right-side view is the coated surface deposited without vibration. By observing the morphologies of the coated surfaces (Figure 5), it is shown that the deposited coating under vibration is more compact, smooth as compared to the coating deposited without vibration.

The EDX analysis shows that the coating on the substrate has considerable amount of carbon particles under vibration $(13 \%)$ and without vibration $(11 \%)$ condition as shown 
(1) lower part

(2) rubber seal between upper part and lower part

(3) clamping bolt

(4) S. S. washer plate

(5) connector

(6) upper part

(7) horn plastic body

(8) connecting wire

(9) plastic dome-like body

(10) metallic connector

(11) horn head

(12) internally threaded hollow pipe

(13) rubber seal between bottom part and hollow pipe

(14) horn clamping bolt

(15) rubber seal between horn body and lower part

(16) rubber seal between bottom part and hollow bolt

(17) hollow bolt

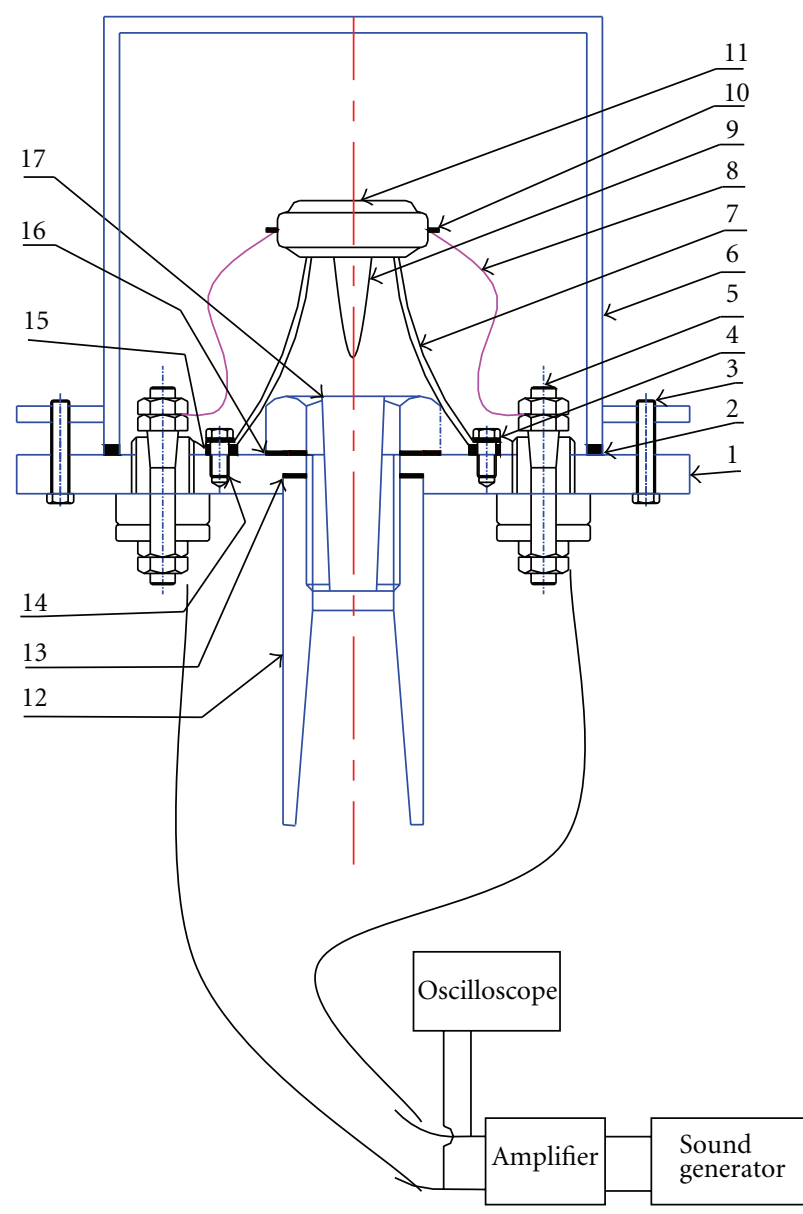

FIgURE 2: Schematic diagram of sound generation system.

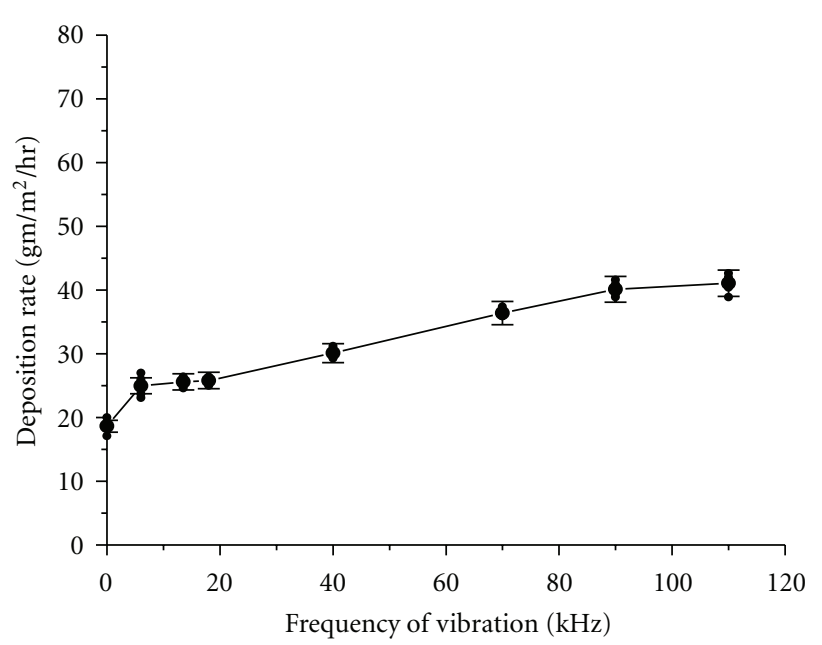

FIgURE 3: Deposition rate as a function of frequency of vibration $\left(T_{\text {sub }}=1000{ }^{\circ} \mathrm{C}, T_{\text {act }}=1900^{\circ} \mathrm{C}, P_{\mathrm{ch}}=25\right.$ Torr, and $\left.d=5 \mathrm{~mm}\right)$.

in Figure 6. This indicates that vibration of sound creates mechanical and pressure wave propagation, which influences the mass transport towards the substrate. As a result, better coating is obtained under sound vibration compared to that without vibration.

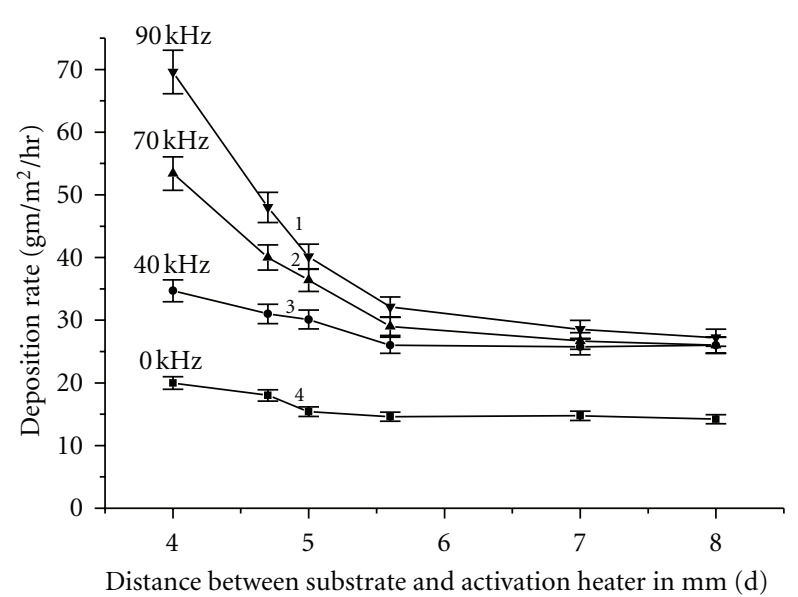

Figure 4: Effect of vibration on deposition rate with respect to distance between substrate and activation heater $\left(T_{\text {sub }}=\right.$ $1000^{\circ} \mathrm{C}, T_{\mathrm{act}}=1900^{\circ} \mathrm{C}$, and $P_{\mathrm{ch}}=25$ Torr $)$.

XRD analysis on specimens is shown in Figure 7 for base metal without coating, coating without sound vibration, and coating with sound vibration. The d-spacings determined from XRD patterns of the existing crystals within the coated layer without and with vibrations are shown in Tables 2 and 3 


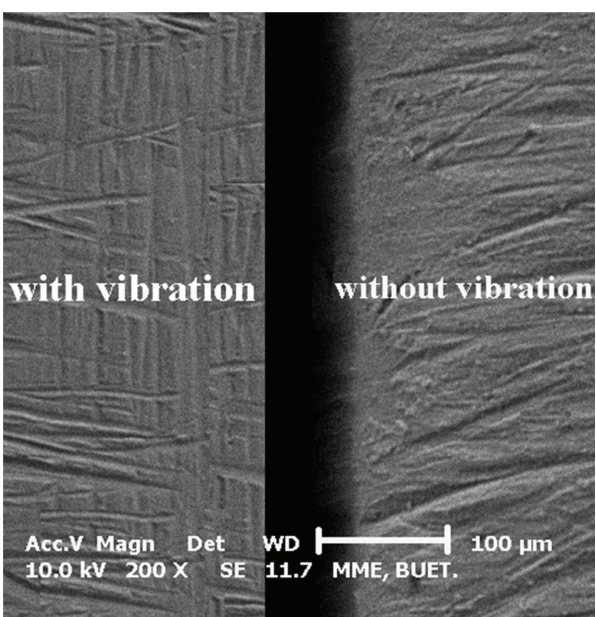

Figure 5: Microstructure (under SEM) of deposited coating under vibration (left-side view) and without vibration (right-side view) condition at different resolutions.

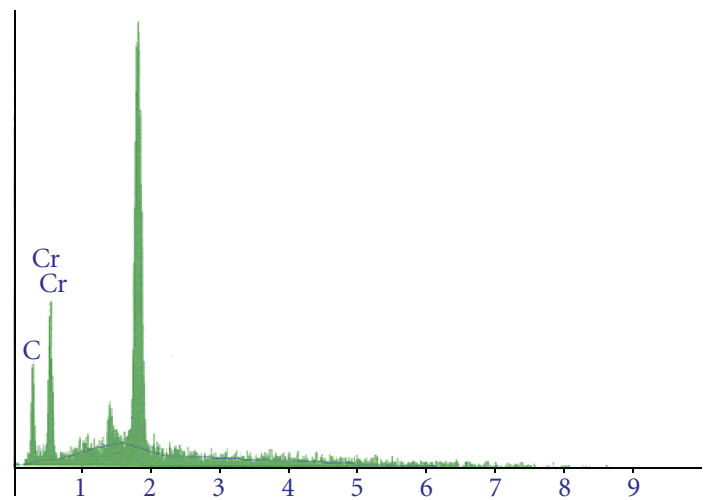

(a)

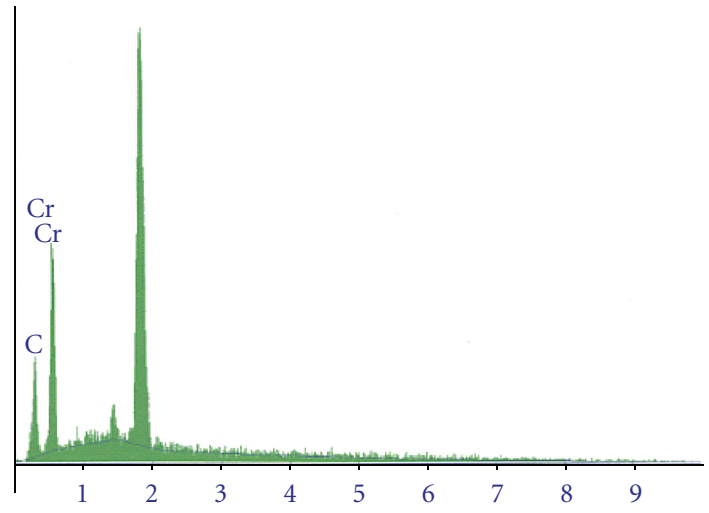

(b)

Figure 6: EDX analysis of coating on substrate with vibration at top and without vibration at bottom $\left(T_{\text {sub }}=1000 \circ \mathrm{C}, T_{\text {act }}=1900 \circ \mathrm{C}\right.$, $P_{\text {ch }}=25$ torr, and $L_{\text {gap }}=5 \mathrm{~mm}$ ).

respectively. They are compared with the standard d-spacings for graphite, diamond, and austenite of austenitic stainless steel. It is found that the values of $\mathrm{d}$-spacings calculated from the observed peaks and from XRD analysis are almost similar

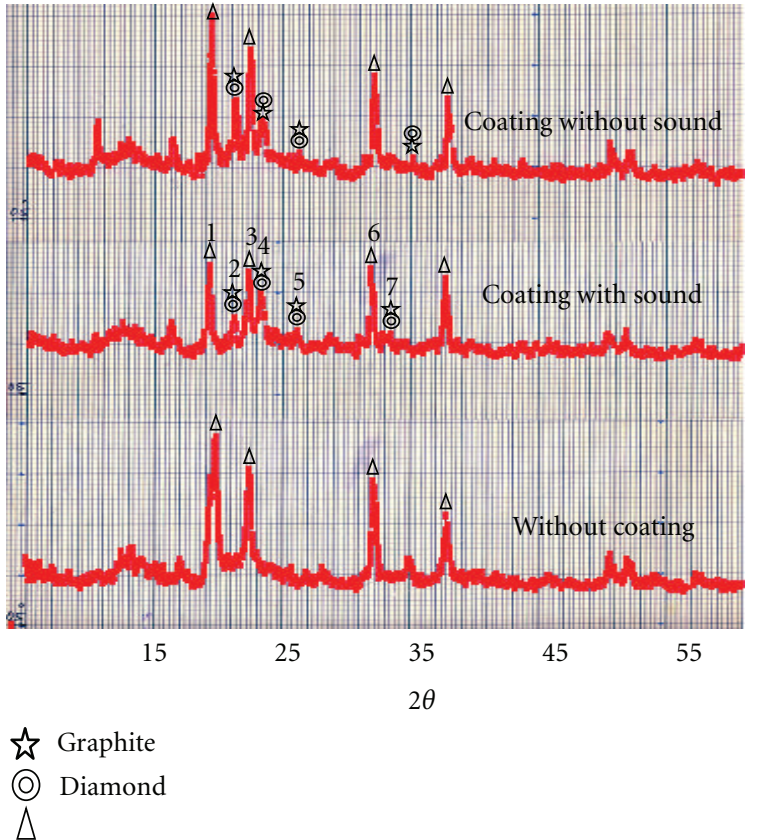

FIGURE 7: XRD analysis of coated surface without sound vibration at top, with sound vibration at middle, and without coating on stainless steel substrate at bottom $\left(S=\right.$ stainless steel $304, T_{\text {sub }}=$ $1000 \circ \mathrm{C}, T_{\mathrm{act}}=1900 \circ \mathrm{C}, P_{\mathrm{ch}}=25$ torr, and $\left.L_{\mathrm{gap}}=5 \mathrm{~mm}\right)$.

with the standard d-spacings values of graphite, diamond, and austenite of austenitic stainless steel.

For comparison of data of area under the significant peaks of Figure 7 indicating the intensity are summarized and presented in Table 4 . The peaks 1, 3, and 6 of these figures indicate the presence of austenite of austenitic stainless steel, and the other peaks of the figures indicate graphite and diamond. The intensity of the peaks 1,3 , and 6 of austenite of austenitic stainless steel substrate without coating are 38, 16 , and 13 units, while for coated substrate without sound vibration are 30,17 , and 11 units, and for coated substrate with vibration are 17,12 , and 10 units. From these data, it is observed that the intensity of the peaks of austenite of austenitic stainless steel decreases in the coated layer due to deposition of carbon. This intensity of the peaks of austenite of austenitic stainless steel with the coated layer under vibration reduces more as compared with the coated layer under no vibration. On the other hand, the intensity of the peaks 2, 4, 5, and 7 of graphite and diamond under no vibration are $12,8,4$, and 4 units and for coating with sound vibration are $9,11,5$, and 5 units. It is seen from these data that the intensity of the peaks of graphite and diamond for the sample coated under vibration increases compared with the coated layer under no vibration that means deposition rate under vibration is better as compared to without vibration.

Possible causes of higher deposition rate, compactness and smoothness of the deposited coating under sound vibration condition can be explained as follows.

The complex chemical and physical processes, which occur during diamond CVD, comprise several different but 
TABLE 2: Comparison of the d-spacings of XRD spectrum of the deposited crystal with the actual d-spacings for graphite, diamond, and Fe $(\gamma)$ without sound.

\begin{tabular}{|c|c|c|c|c|c|c|c|c|c|}
\hline \multirow{2}{*}{$\begin{array}{l}\text { Peak } \\
\text { number }\end{array}$} & \multirow{2}{*}{$2 \theta$} & \multirow{2}{*}{$\begin{array}{l}\text { Measured } \\
d(\mathrm{~A})\end{array}$} & \multirow{2}{*}{$i / i_{0}$} & \multicolumn{2}{|c|}{ Diamond } & \multicolumn{2}{|c|}{ Graphite } & \multicolumn{2}{|c|}{$\mathrm{Fe}(\gamma)$} \\
\hline & & & & $(h k l)$ & $d(\mathrm{~A})$ & $(h k l)$ & $d(\mathrm{~A})$ & $(h k l)$ & $d(\mathrm{~A})$ \\
\hline (1) & 19.5 & 2.0982 & 89 & & & & & 111 & 2.095 \\
\hline (2) & 21.2 & 1.9317 & 64 & 105 & 1.930 & 103 & 1.9200 & & \\
\hline (3) & 22.5 & 1.8214 & 86 & & & & & 200 & 1.8214 \\
\hline (4) & 23.3 & 1.7597 & 53 & 108 & 1.6650 & 104 & 1.7950 & & \\
\hline (5) & 26.0 & 1.5796 & 14 & 109 & 1.5800 & 106 & 1.5400 & & \\
\hline (6) & 32.6 & 1.2660 & 100 & & & & & 220 & 1.283 \\
\hline (7) & 33.4 & 1.2365 & 14 & $101 \underline{4}$ & 1.2200 & 110 & 1.2280 & & \\
\hline
\end{tabular}

TABLE 3: Comparison of the $d$-spacings of XRD spectrum of the deposited crystal with the actual d-spacings for graphite, diamond, and Fe $(\gamma)$ with sound.

\begin{tabular}{|c|c|c|c|c|c|c|c|c|c|}
\hline \multirow{2}{*}{$\begin{array}{l}\text { Peak } \\
\text { number }\end{array}$} & \multirow{2}{*}{$2 \theta$} & \multirow{2}{*}{$\begin{array}{l}\text { Measured } \\
d(\mathrm{~A})\end{array}$} & \multirow{2}{*}{$i / i_{0}$} & \multicolumn{2}{|c|}{ Diamond } & \multicolumn{2}{|c|}{ Graphite } & \multicolumn{2}{|c|}{$\mathrm{Fe}(\gamma)$} \\
\hline & & & & $(h k l)$ & $d(\mathrm{~A})$ & $(h k l)$ & $d(\mathrm{~A})$ & $(h k l)$ & $d(\mathrm{~A})$ \\
\hline (1) & 19.5 & 2.0982 & 92 & & & & & 111 & 2.095 \\
\hline (2) & 21.2 & 1.9317 & 42 & 105 & 1.930 & 103 & 1.9200 & & \\
\hline (3) & 22.5 & 1.8214 & 100 & & & & & 200 & 1.8214 \\
\hline (4) & 23.3 & 1.7597 & 83 & 108 & 1.6650 & 104 & 1.7950 & & \\
\hline (5) & 26.0 & 1.5796 & 17 & 109 & 1.5800 & 106 & 1.5400 & & \\
\hline (6) & 32.6 & 1.2660 & 75 & & & & & 220 & 1.283 \\
\hline (7) & 33.4 & 1.2365 & 21 & $101 \underline{4}$ & 1.2200 & 110 & 1.2280 & & \\
\hline
\end{tabular}

TABLE 4: Comparison of intensity among substrate without coating, coating without sound vibration and coating with sound vibration.

\begin{tabular}{|c|c|c|c|c|c|c|c|}
\hline & & & & Serial numbe & & & \\
\hline & 1 & 2 & 3 & 4 & 5 & 6 & 7 \\
\hline \multirow{3}{*}{ Conditions } & & \multirow{3}{*}{$\begin{array}{c}21.2 \\
\text { Diamond/ } \\
\text { gaphite }\end{array}$} & & $2 \theta$ & \multirow{3}{*}{$\begin{array}{l}26.0 \\
\text { Diamond/ } \\
\text { graphite }\end{array}$} & & \multirow{3}{*}{$\begin{array}{c}33.4 \\
\text { Graphite/ } \\
\text { diamond }\end{array}$} \\
\hline & 19.5 & & 22.5 & 23.3 & & 32.6 & \\
\hline & $\mathrm{Fe}(\gamma)$ & & $\mathrm{Fe}(\gamma)$ & $\begin{array}{l}\text { Graphite/ } \\
\text { diamond } \\
\text { intensity (I) }\end{array}$ & & $\mathrm{Fe}(\gamma)$ & \\
\hline $\begin{array}{l}\text { Substrate } \\
\text { without coating }\end{array}$ & 38 & & 16 & & & 13 & \\
\hline $\begin{array}{l}\text { Substrate with } \\
\text { coating without } \\
\text { sound vibration }\end{array}$ & 30 & 12 & 17 & 8 & 3.5 & 11 & 4 \\
\hline $\begin{array}{l}\text { Substrate with } \\
\text { coating with } \\
\text { sound vibration }\end{array}$ & 17 & 9 & 12 & 11 & 5 & 10 & 5 \\
\hline
\end{tabular}

interrelated features. The process gases of the chamber before diffusing toward the substrate surface pass through an activation region (a hot filament), which provide energy to the gaseous species. This activation causes molecules to fragment into reactive radicals and atoms, creates ions and electrons, and heats the gas up to temperatures approaching a few thousand Kelvin. Beyond the activation region, these reactive fragments continue to mix and undergo a complex set of chemical reactions until they strike the substrate surface. At this point, the species is adsorbed and entrapped within the surface, some portions are desorbed again back into the gas phase, or diffuse around close to the surface until an appropriate reaction site is found. If a surface reaction occurs, one possible outcome, if all the conditions are suitable, is diamond. During this process, the addition of sound vibration might increase the energy level of the depositing species. The increase of deposition rate and the surface quality of the deposited coating might be due to elimination or reduction of the potential barrier [14] during the chemical activity by adding some extra sound energy. This extra sound energy may work on the deposition process in the following ways:

(i) due to the sound media, particles vibrate back and forth and for equilibrium condition, some extra energy remains in the process [15] during the introduction of extra sound vibration into the system;

(ii) at constant temperature, the amount of adsorption depends on pressure [16-18]. Pressure value of sound increases the local pressure; 
(iii) as movement of the particles increase, the concentration of diffusing carbon elements increases [19]. Therefore, the diffusion rate of the coating may increase;

(iv) extra vibration of sound may increase the momentum difference of carbon and hydrogen due to their atomic mass difference in methane $\left(\mathrm{CH}_{4}\right)$ molecule [15]. This might enhance the chemical reaction in CVD process, and ultimately the deposition rate may increase.

The results obtained under this study shows that sound vibration increases deposition rate with more compact and smoother surface finish. Similar study is conducted to observe the effects of ultrasonic vibrations on the localized electrochemical deposition (LECD) process by Yeo et al. [13] According to their results, ultrasonic vibrations increase the rate of deposition and improve the concentricity of the fabricated microcolumns. Ultrasonic vibrations perpendicular to the deposition plane improved the uniformity of vapordeposited films by intensifying diffusion. The effect increases with increasing intensity. Ultrasonic vibrations normal to the deposition surface increase the film thickness. These results confirm our findings in the present study.

\section{Conclusions}

The following can be concluded from this study:

(1) deposition rate increases significantly (about 18\% higher) under sound vibration condition than that of no sound vibration condition;

(2) the deposition rate under sonic vibration increases slightly with the frequency of vibration;

(3) the deposition rate under ultrasonic vibration increases significantly with the frequency of vibration up to a certain value, and after that value, the deposition rate remains almost constant;

(4) for a particular frequency of vibration, the deposition rate decreases with the distance up to a certain value, and after that the deposition rate remains almost constant (up to observed distance);

(5) percentage of diamond/graphite in the deposited coating increases about $10 \%$ with the addition of sound vibration;

(6) the surface morphology under SEM analysis of the deposited coatings under sound vibration condition is observed as more compact and smoother surface finish than that of without vibration condition.

Therefore, by maintaining an appropriate level of frequency of vibration and the distance between substrate and activation heater deposition rate of Carbon (diamond/graphite) may be maintained to higher value.

\section{Notations}

$T_{\text {sub }}$ : Substrate heater temperature

$T_{\text {act }}$ : Activation heater temperature

$L_{\text {gap }}:$ Distance between substrate and activation heater

$P_{\text {ch }}:$ Pressure of the reactor chamber.

\section{References}

[1] H. O. Pierson, Handbook of Chemical Vapor Deposition, Noyes, Norwich, NY, USA, 2nd edition, 1999.

[2] R. F. Bunshah, Handbook of Deposition Technologies for Films and Coatings, Noyes, NJ, USA, 2nd edition, 1994.

[3] L. L. Regel and W. R. Wilcox, "Diamond film deposition by chemical vapor transport," Acta Astronautica, vol. 48, no. 2-3, pp. 129-144, 2001.

[4] C. H. M. Van Der Werf, H. D. Goldbach, J. Löffler et al., "Silicon nitride at high deposition rate by Hot Wire Chemical Vapor Deposition as passivating and antireflection layer on multicrystalline silicon solar cells," Thin Solid Films, vol. 501, no. 1-2, pp. 51-54, 2006.

[5] E. J. Corat and D. G. Goodwin, "Temperature dependence of species concentrations near the substrate during diamond chemical vapor deposition," Journal of Applied Physics, vol. 74, no. 3, pp. 2021-2029, 1993.

[6] M. C. McMaster, W. L. Hsu, M. E. Coltrin, D. S. Dandy, and C. Fox, "Dependence of the gas composition in a microwave plasma-assisted diamond chemical vapor deposition reactor on the inlet carbon source: $\mathrm{CH}_{4}$ versus $\mathrm{C}_{2} \mathrm{H}_{2}$," Diamond and Related Materials, vol. 4, no. 7, pp. 1000-1008, 1995.

[7] Y. Fu, C. Q. Sun, H. Du, and B. Yan, "From diamond to crystalline silicon carbonitride: Effect of introduction of nitrogen in $\mathrm{CH}_{4} / \mathrm{H}_{2}$ gas mixture using MW-PECVD," Surface and Coatings Technology, vol. 160, no. 2-3, pp. 165-172, 2002.

[8] L. L. Regel and W. R. Wilcox, "Deposition of diamond on graphite and carbon felt from graphite heated in hydrogen at low pressure," Journal of Materials Science Letters, vol. 19, no. 6, pp. 455-457, 2000.

[9] W. Yuan, M. Banan, L. L. Regel, and W. R. Wilcox, "The effect of vertical vibration of the ampoule on the directional solidification of InSbGaSb alloy," Journal of Crystal Growth, vol. 151, no. 3-4, pp. 235-242, 1995.

[10] L. Chowa, D. Zhoub, A. Hussainb et al., "Chemical vapor deposition of novel carbon materials," Thin Solid Films, vol. 368, pp. 193-197, 2000.

[11] D. S. Dandy and M. E. Coltrin, "Relationship between diamond growth rate and hydrocarbon injector location in direct-current arcjet reactors," Applied Physics Letters, vol. 66, no. 3, 3 pages, 1995.

[12] S. Kumar, P. N. Dixit, D. Sarangi, and R. Bhattacharyya, "High rate deposition of diamond like carbon films by very high frequency plasma enhanced chemical vapor deposition at $100 \mathrm{MHz}$," Journal of Applied Physics, vol. 93, no. 10, pp. 63616369, 2003.

[13] S. H. Yeo, J. H. Choo, and K. H. A. Sim, "On the effects of ultrasonic vibrations on localized electrochemical deposition," Journal of Micromechanics and Microengineering, vol. 12, no. 3, pp. 271-279, 2002.

[14] T. Burakowski and T. Wierzchon, Surface Engineering of Metal, CRC Press, New York, NY, USA, 2000.

[15] B. Bhushan, Principles and Applications of Tribology, A WileyInterscience, New York, NY, USA, 1999. 
[16] J. Oscik, Adsorption, E. Horwood Lim, Chichester, UK, 1982.

[17] F. C. Tompkins, Chemisorption of Gases on Metals, PWN, Warsaw, Poland, 1985.

[18] Joint Report, Physical Chemistry, PWN, Warsaw, Poland, 2nd edition, 1965

[19] S. Mrowec, "Selected topics from the chemistry of defects and theory of diffusion in the solid state," Geological Publication, Warsaw, Poland, 1974. 

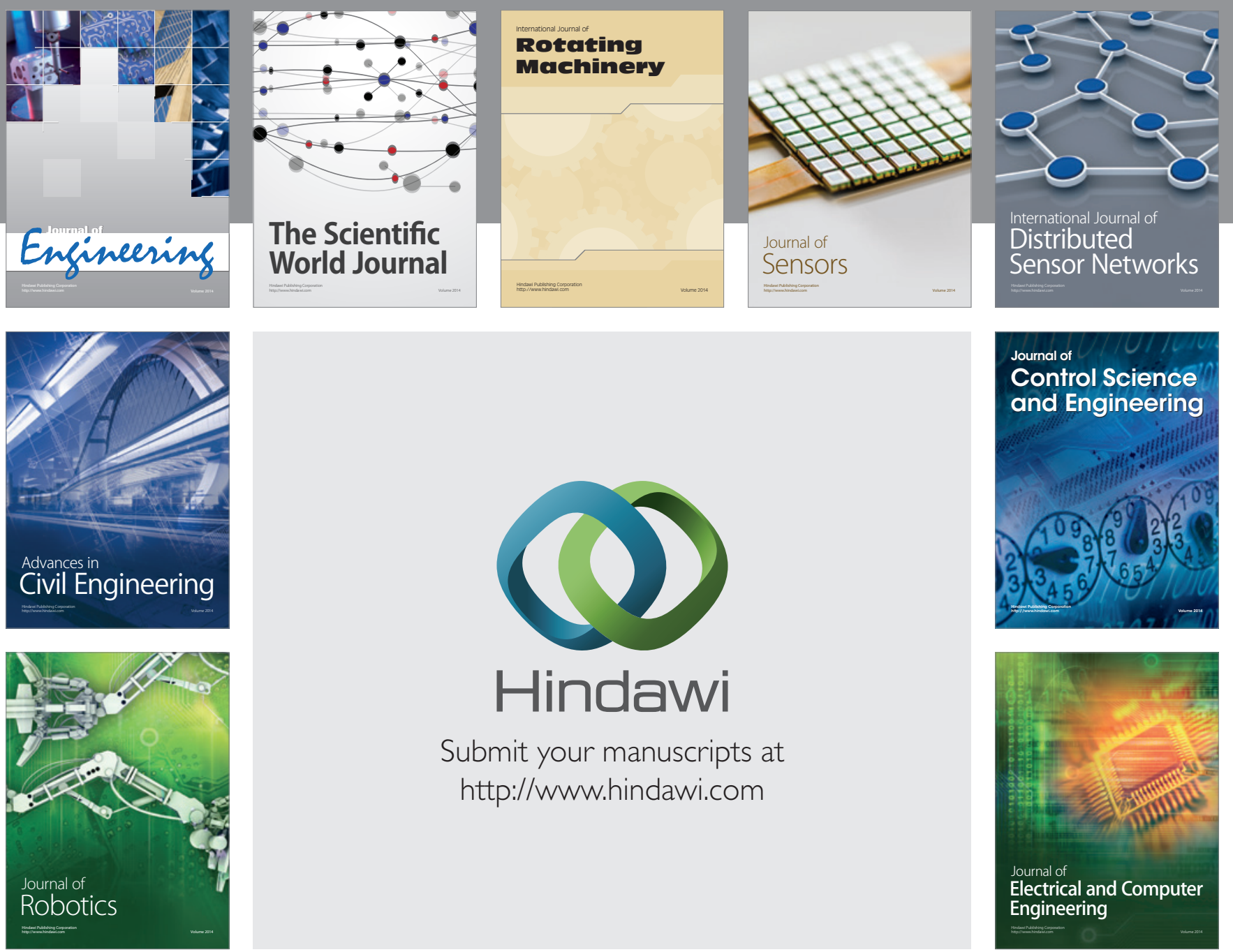

Submit your manuscripts at

http://www.hindawi.com
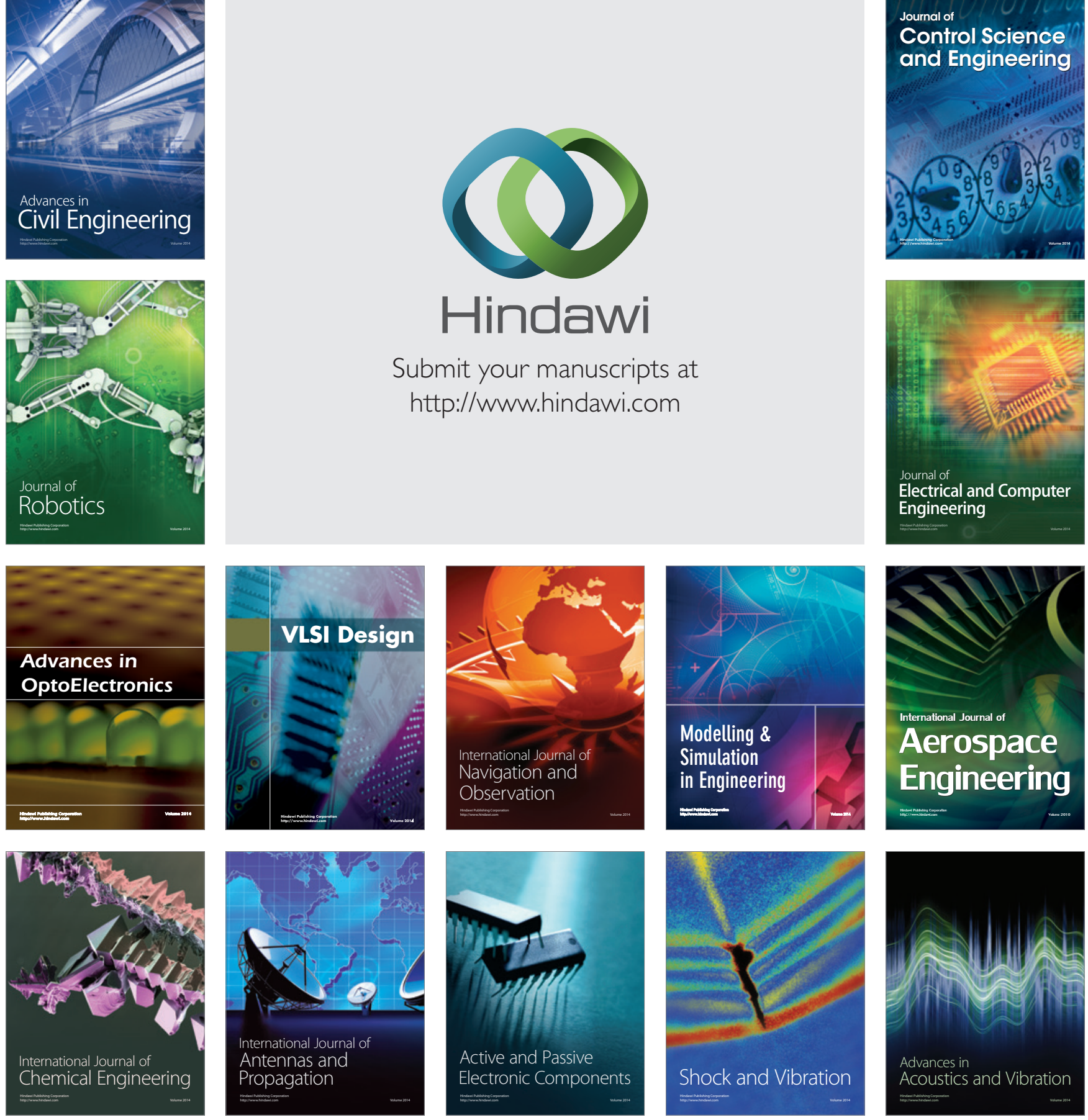